\title{
The NASA Lunar Impact Monitoring Program
}

\author{
Rob Suggs
}

Space Environments Team Lead and

NASA Meteoroid Environment Office

May 28, 2008 


\section{Why Lunar Impact Monitoring is Useful}

- We started this work in earnest 2 years ago to provide a better estimate of the ejecta environment for Constellation lunar elements.

- It turns out that it is also useful for calibration of MEM for large ( $\mathrm{kg})$ masses. 


\section{Why are lunar impact monitoring and hypervelocity impact testing necessary for Constellation?}

- Constellation Program needs a specification for lunar impact ejecta

- Existing spec is for Apollo - circa 1969

- Astronauts will be exposed to this environment for months as opposed to hours.

- Flux of larger objects (kilogram size) is poorly determined

- Production of ejecta particles is very poorly determined

- We must:

- Measure the flux and brightness of large impactors - ALAMO

- Determine the luminous efficiency - fraction of impact kinetic energy which converts to light (which we observe) - Ames Vertical Gun Range

- That gives the flux vershis size of mpactors

- Measure the ejecta properties (-nass, speed, direction distributions) and use modeling to extend from test regime to lunar regime

- Use model to fly the particles and estjmate flux vs size and velocity at a lunar olutpost.

- EV44 houses the Meteoroid Environment Office and the Constellation Environments and Constraints System Integration Group lead - we have the responsibility 10 do this job. 


\section{Jack Schmitt/Apollo 17 observation of lunar impact}
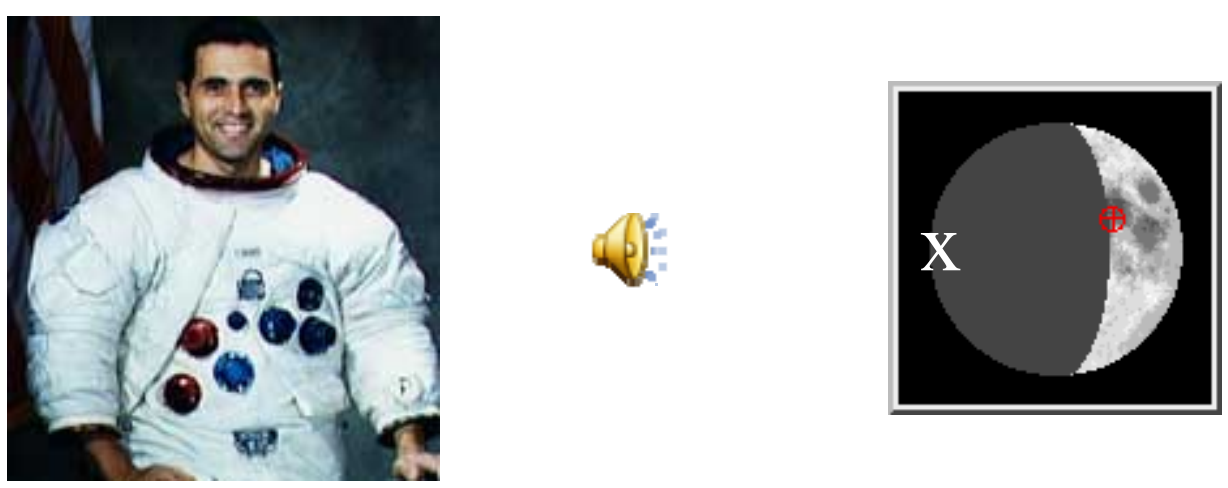

"NASA Apollo 17 transcript" discussion is given below (before descent to lunar surface):

03153809 (mission elapsed time)

(10 Dec 1972, 21:16:09 UT - possible Geminid)

LMP Hey, I just saw a flash on the lunar surface!

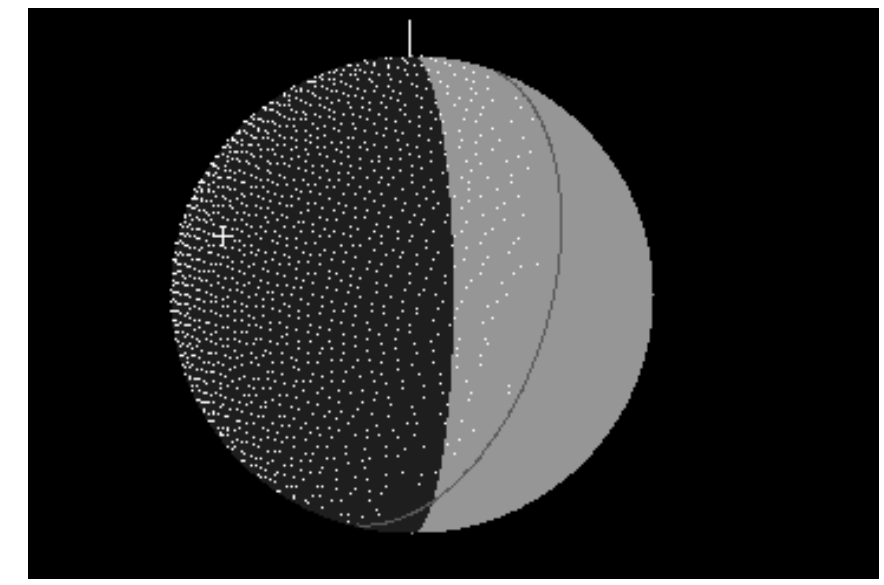

$\mathrm{CC}$ Oh, yes?

LMP It was just out there north of Grimaldi [mare]. Just north of Grimaldi. You might see if you got anything on your seismometers, although a small impact probably would give a fair amount of visible light.

CC Okay. We'll check.

LMP It was a bright little flash right out there near that crater. See the [sharp rimed] crater right at the [north] edge of [the] Grimaldi [mare]? Then there is another one [i.e., sharp rimed crater] [directly] north of it [about $50 \mathrm{~km}$ ]- fairly sharp one north of it. [That] is where there was just a thin streak [pin prick] [flash?] of light.

CC How about putting an $\mathrm{X}$ on the map where you saw it?

LMP I keep looking for -- yes, we will. I was planning on looking for those kind of things.... 


\section{Current (1969) Ejecta Model from SP-8013}

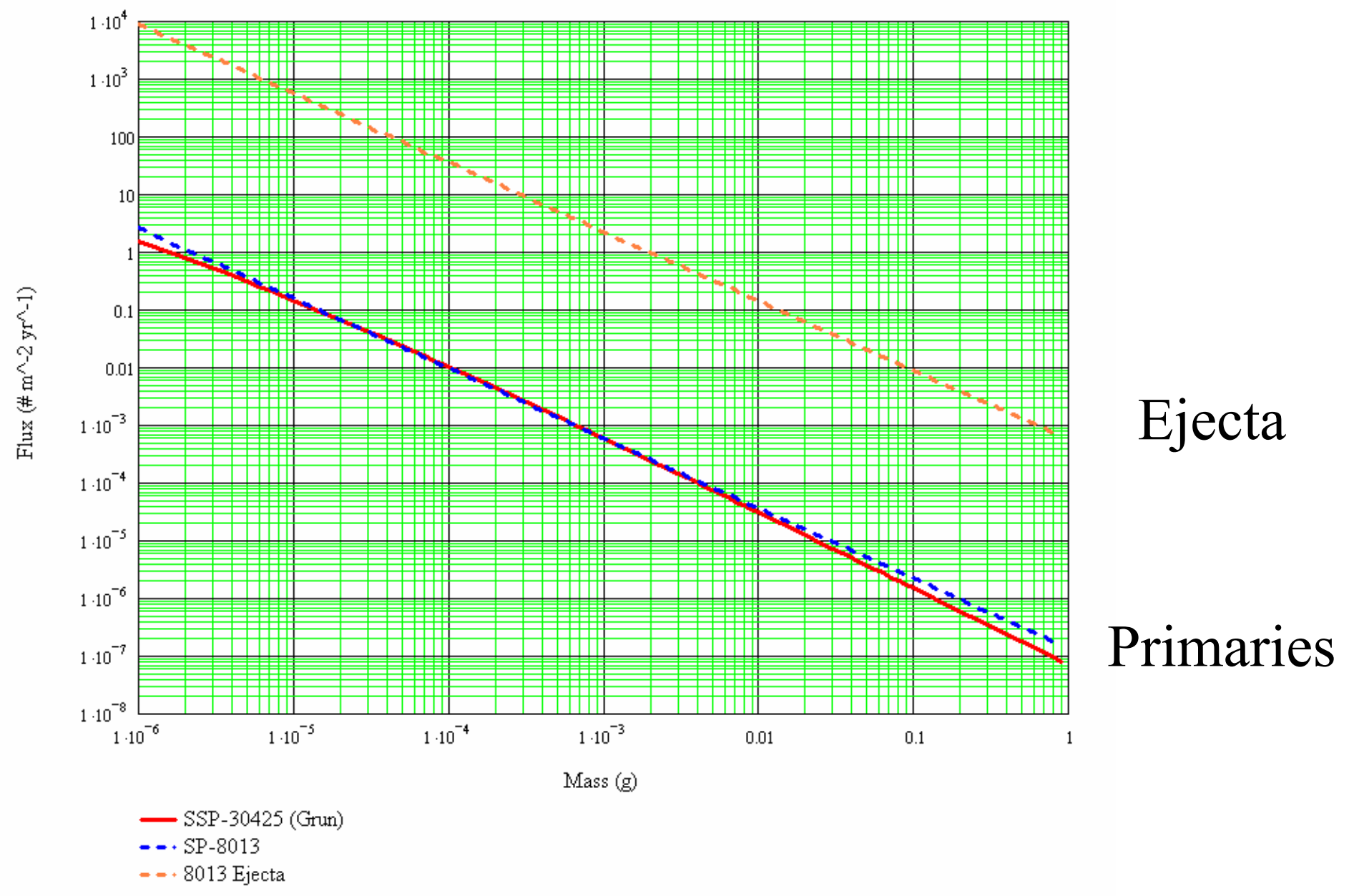

Ejecta particles are 10,000 times as abundant as primaries! This curve is unphysical. 


\section{Impact Observation Technique}

- Dark (not sunlit) side only

- Earthshine illuminates lunar features

- Crescent and quarter phases -0.1 to 0.5 solar illumination

- 5 nights waxing (evening)

- 5 nights waning (morning)

- 4-6 nights of data a month, weather dependent

- 3 telescopes

- 20 inch $(0.5 \mathrm{~m})$ and 2 x 14 inch $(0.35 \mathrm{~m})$

- StellaCam EX and Watec H2 cameras

- Observing procedure

- Aim scope at Moon

- Record video to harddrive

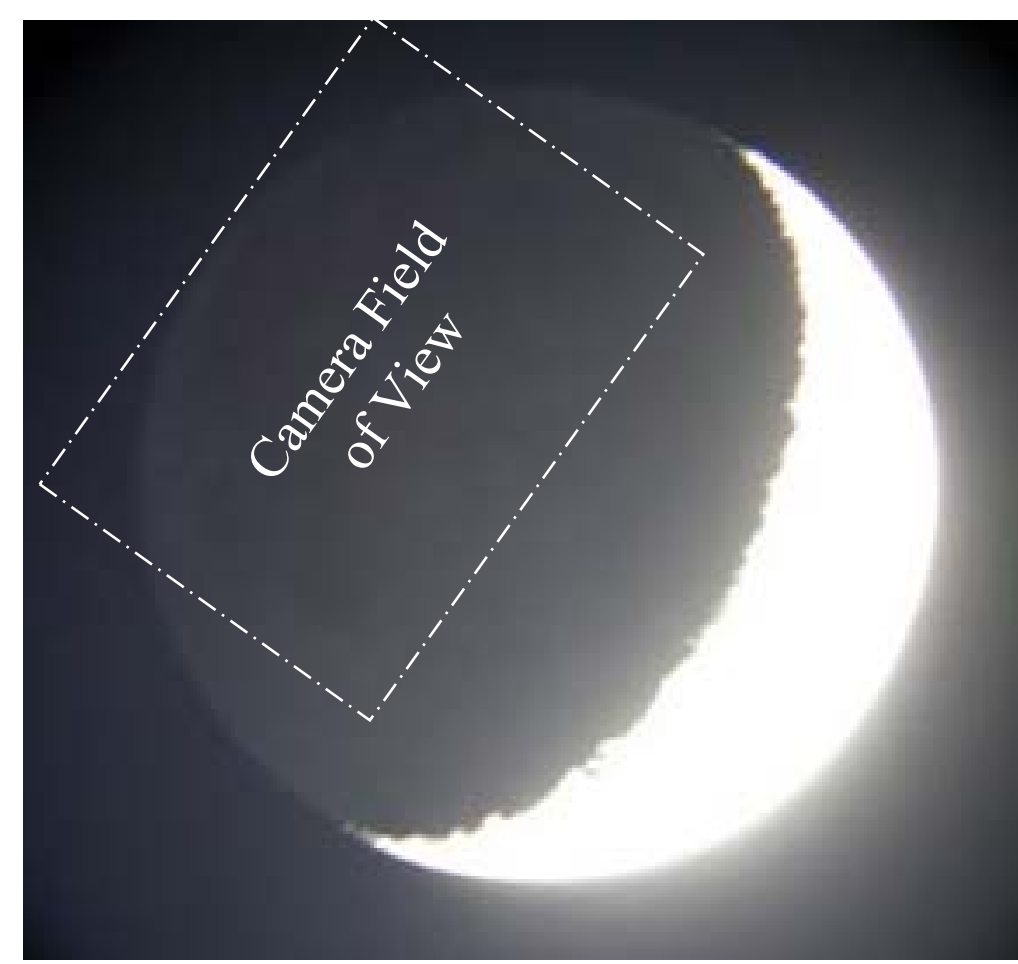

- CCD camera $\rightarrow$ Digital 8 recorder $\rightarrow$ hard drive

- Wait and reposition 


\section{Automated Lunar and Meteor Observatory}




\section{$0.5 \mathrm{~m}$ in dome on left, $0.35 \mathrm{~m}$ in tower}

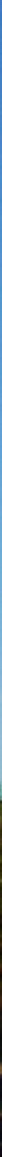




\section{0 inch $(0.5 \mathrm{~m}) \mathrm{RCOS}$}

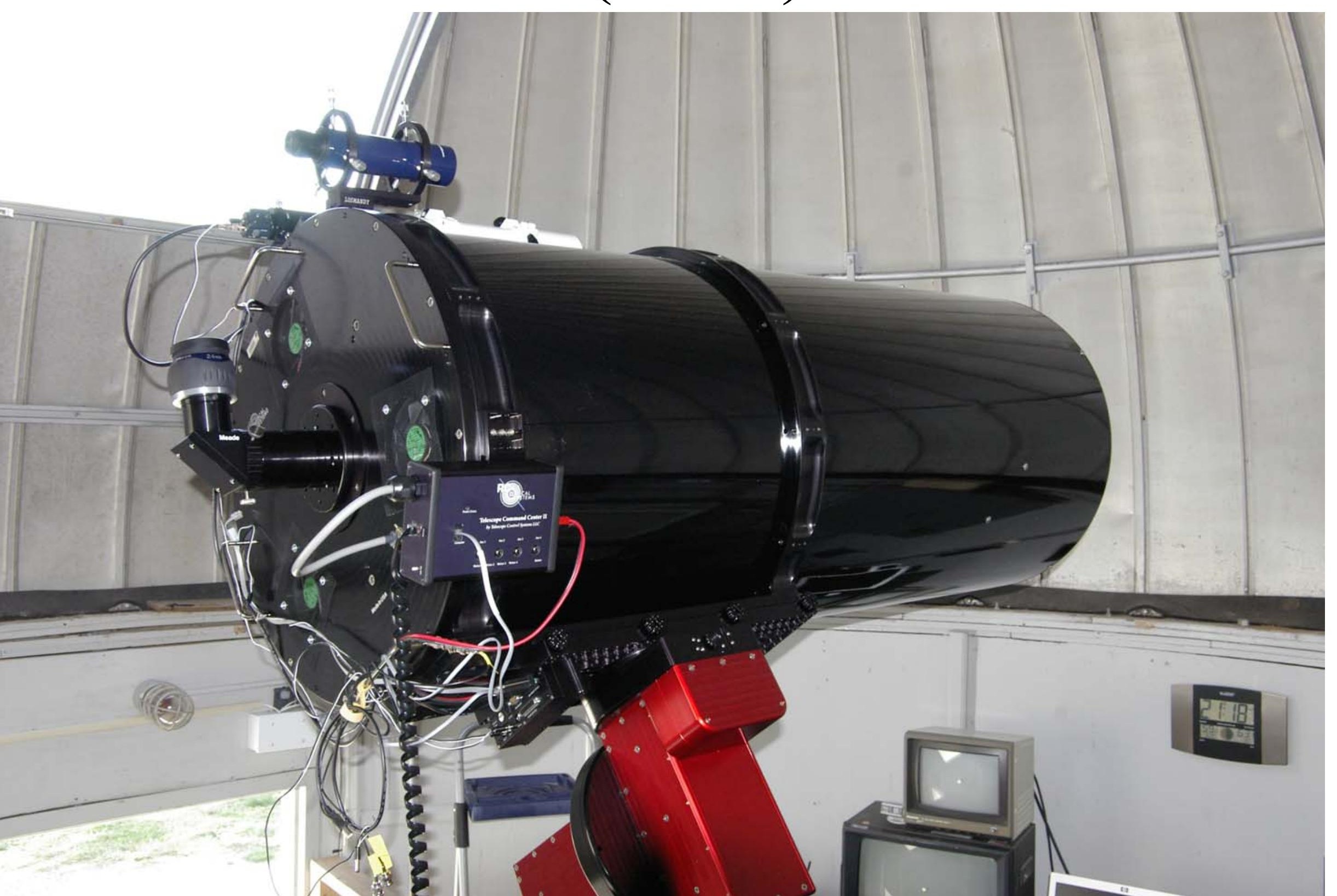




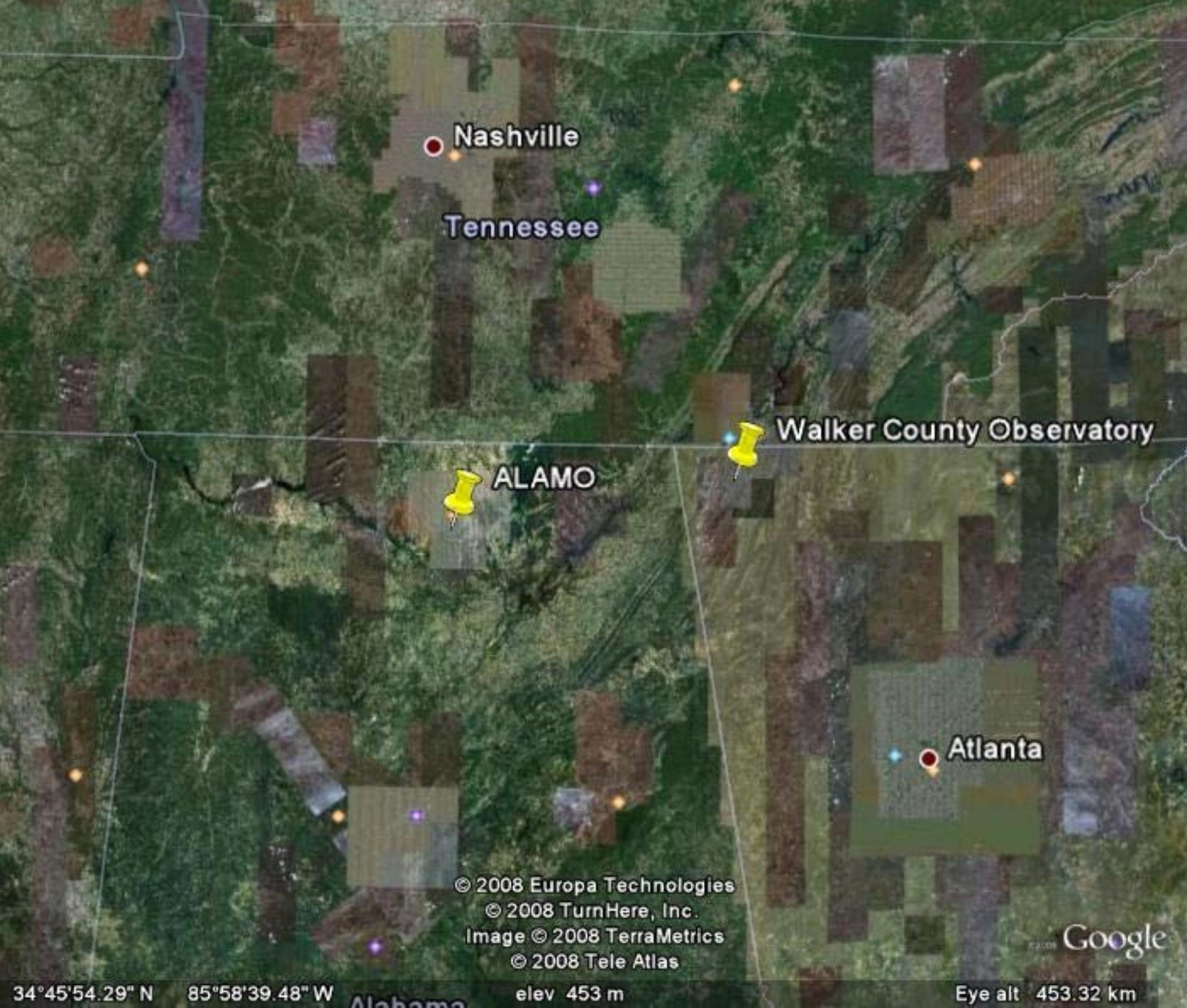




\section{Walker County Observatory}

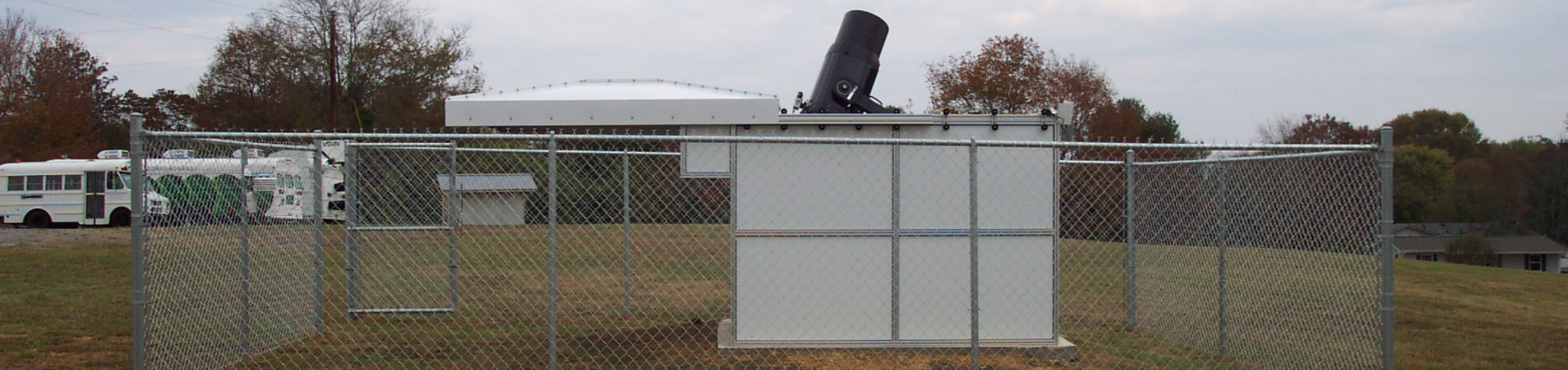




\section{Meade 14 in $(0.35 \mathrm{~m})$}

-

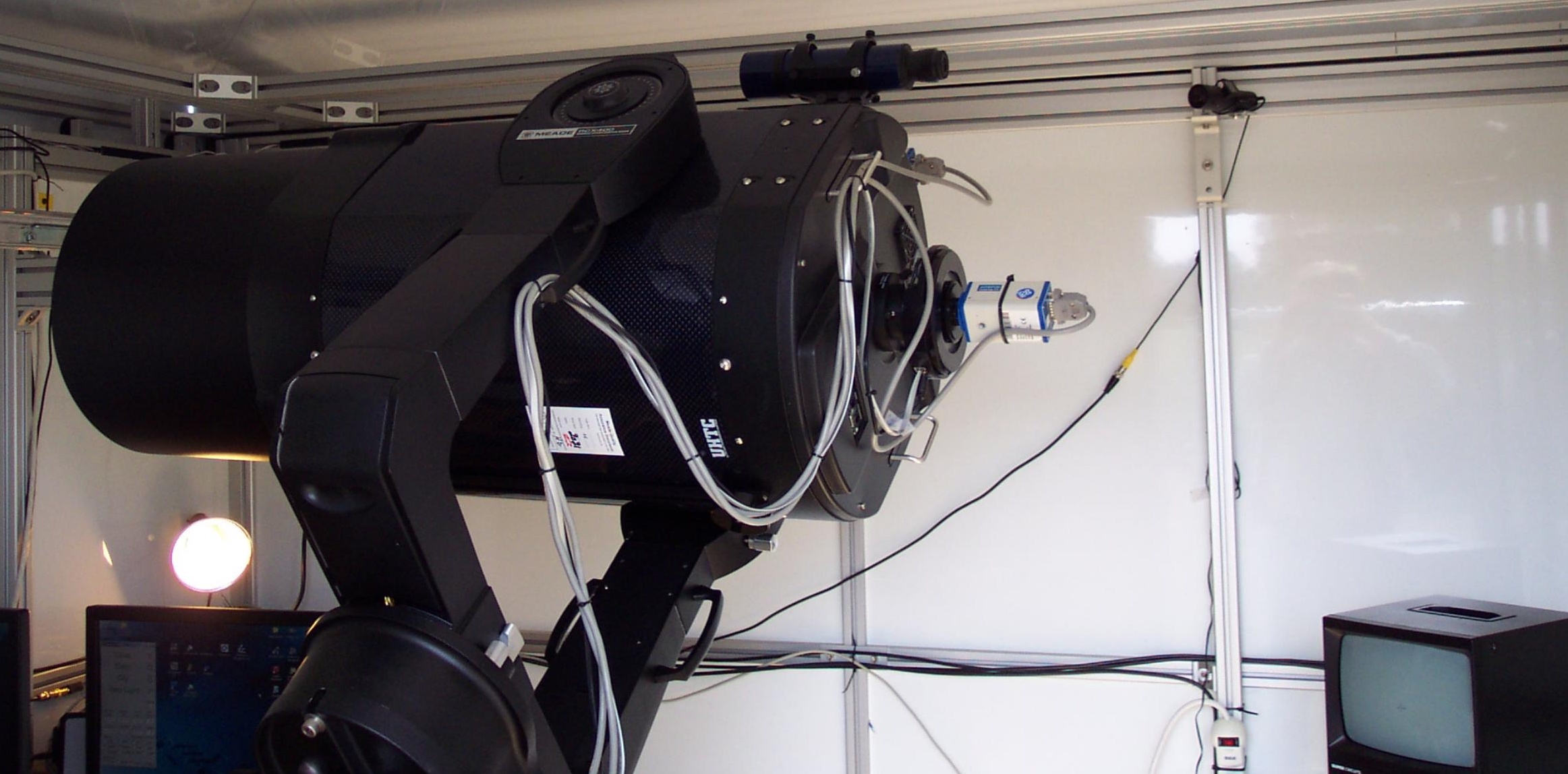




\section{Control Room}

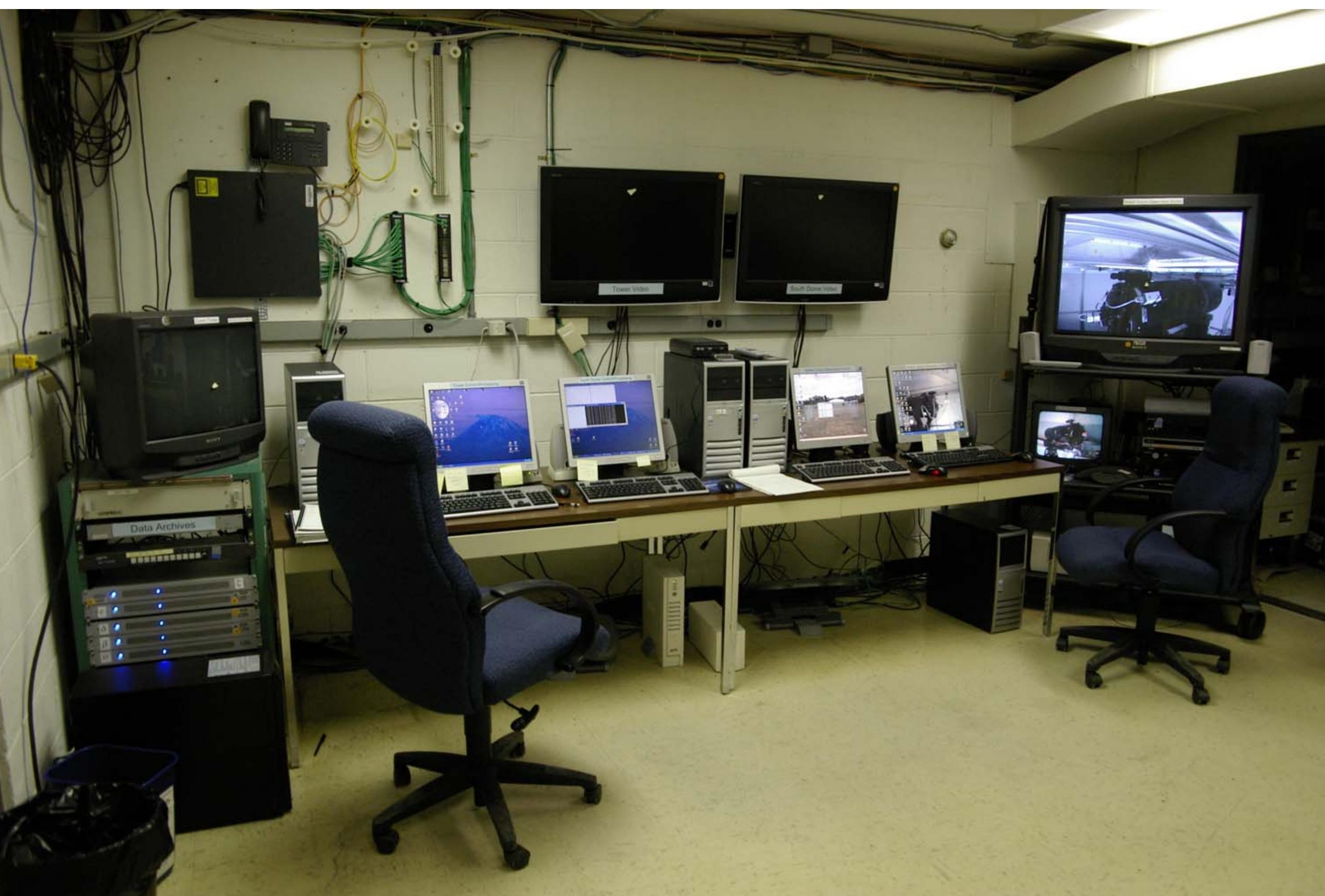




\section{Operator position}

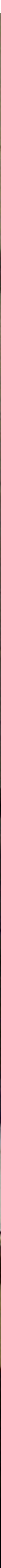




\section{Probable Leonid Impact November 17, 2006}

Video is slowed by a factor of 7 


\section{Video of multiple impacts}




\section{LunarScan (Gural)}

\section{Impact 15 Dec 2006}

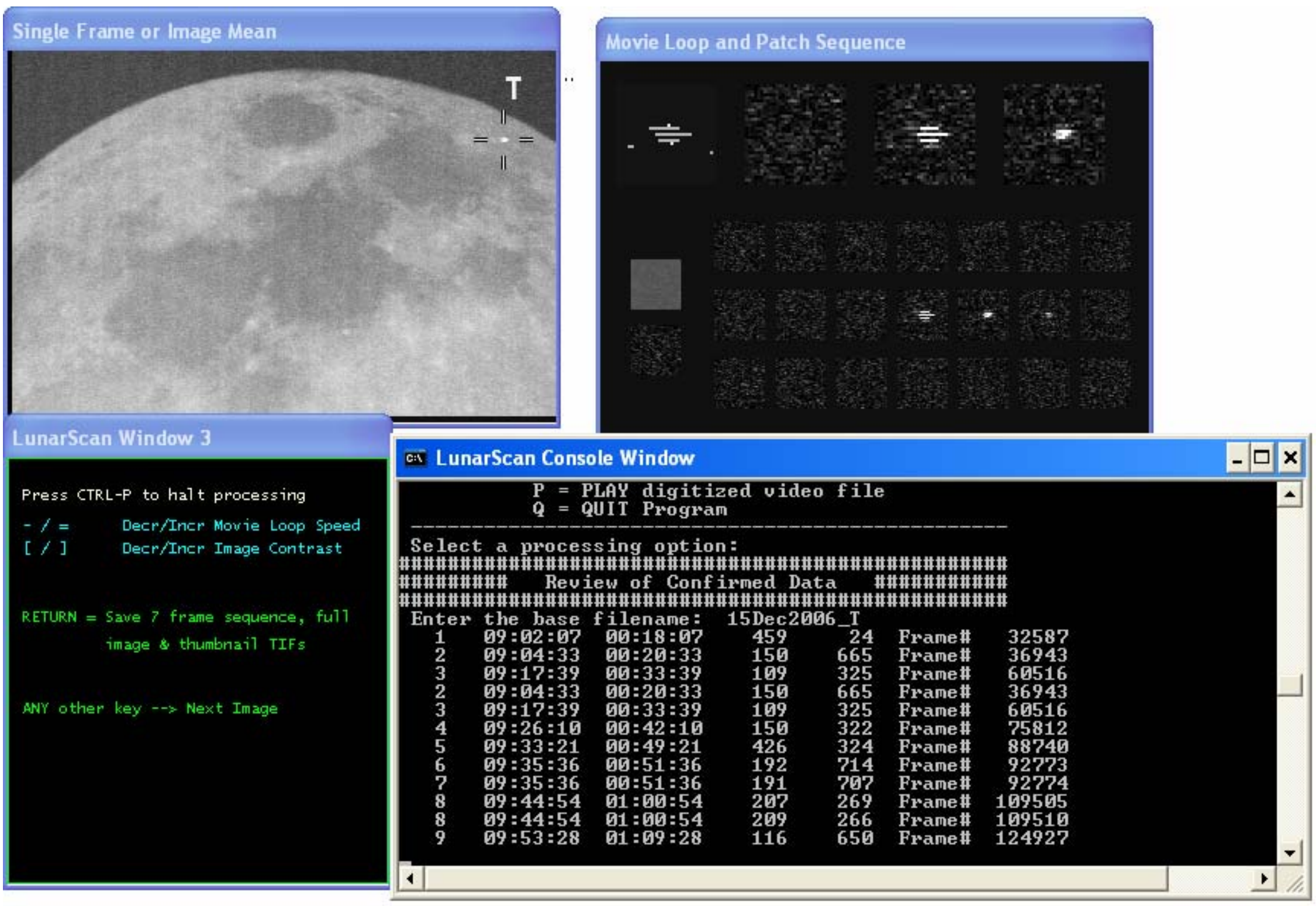




\section{Data Analysis Pipeline}
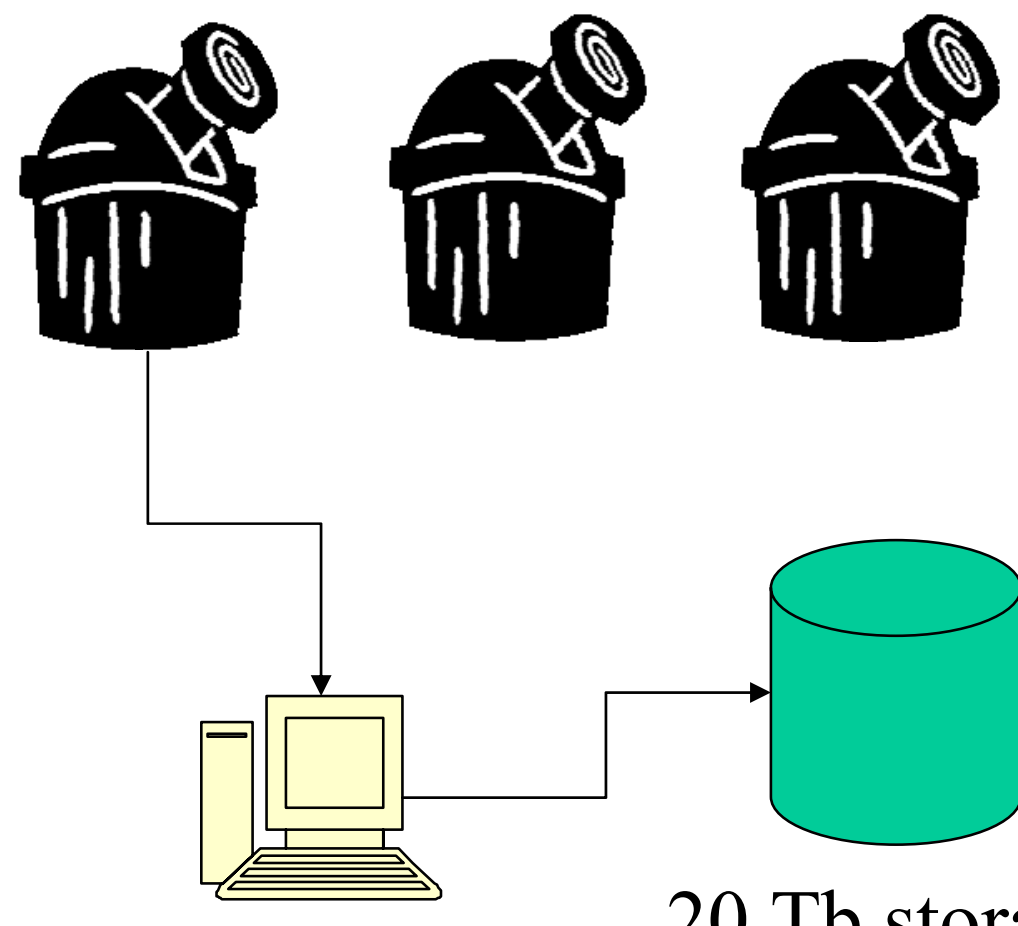

Data collection and telescope control

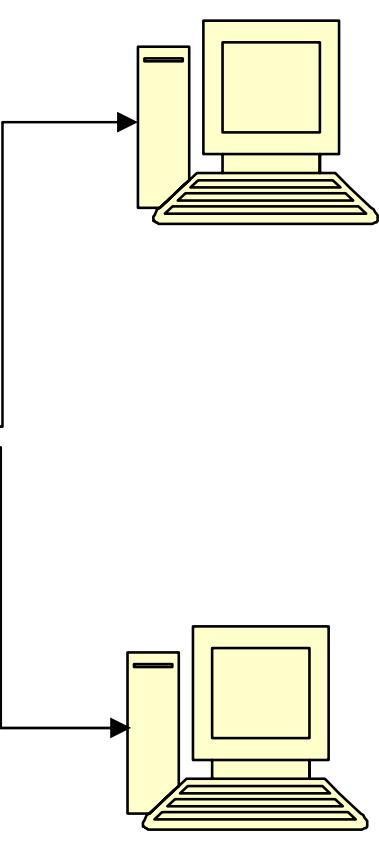

LunarScan finds flashes

\section{LunaCon}

flash photometry collecting area, detection limit, time on target of all video

Must detect flash in all operating telescopes 


\section{The Usual Suspects}

- Noise

- Boundaries

- Stars

- Satellite glints

- Impacts

- Established WCO site to discriminate faint glints from orbital debris

0 Lunar Flash Suspect Editor G:Lunar_VideolMay2006May2.avi $\square \square$
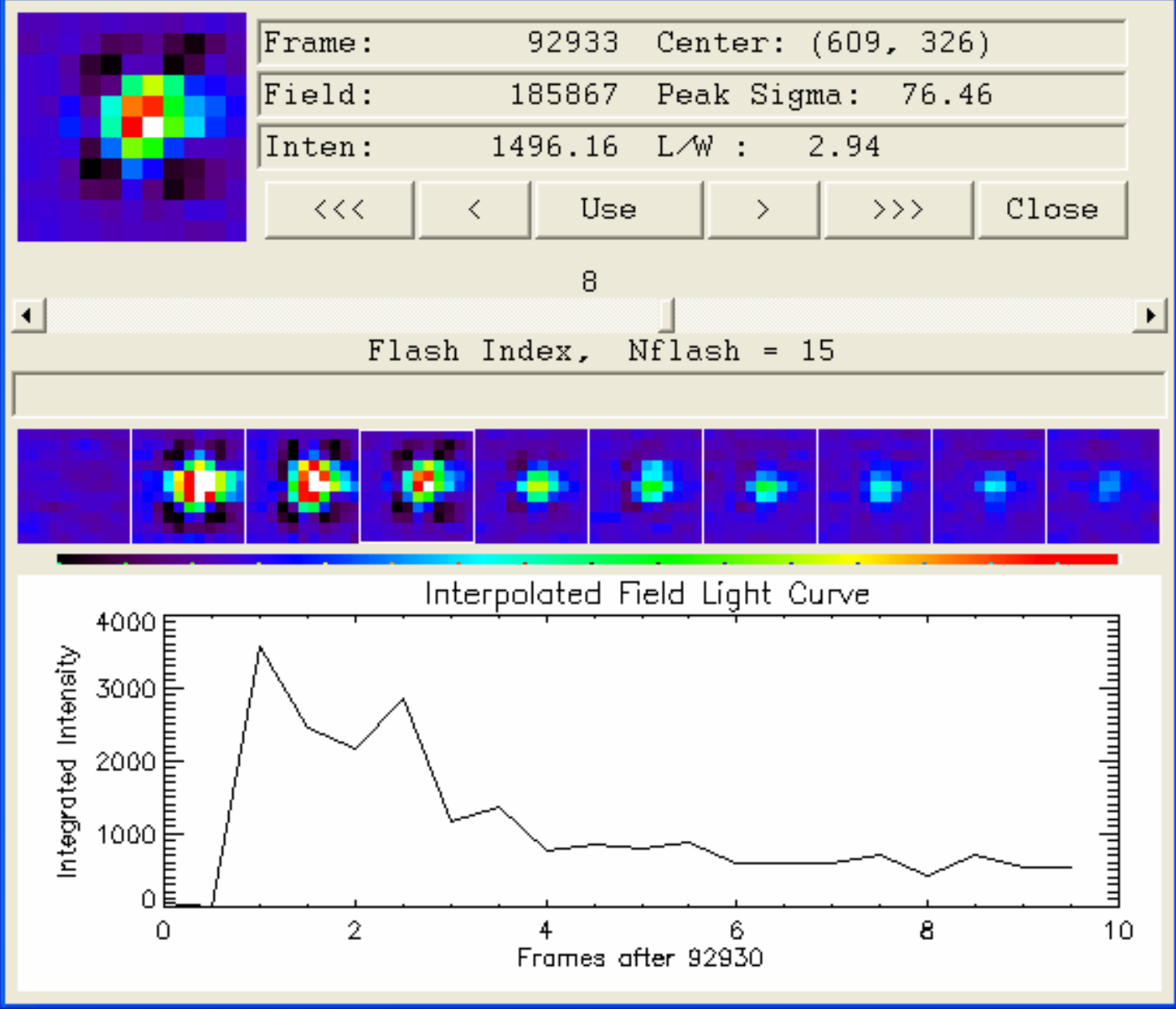


\section{Atlas-Centaur Debris}

16 Dec. 2006

Half real-time 


\section{Impact Candidates - over 100 now}

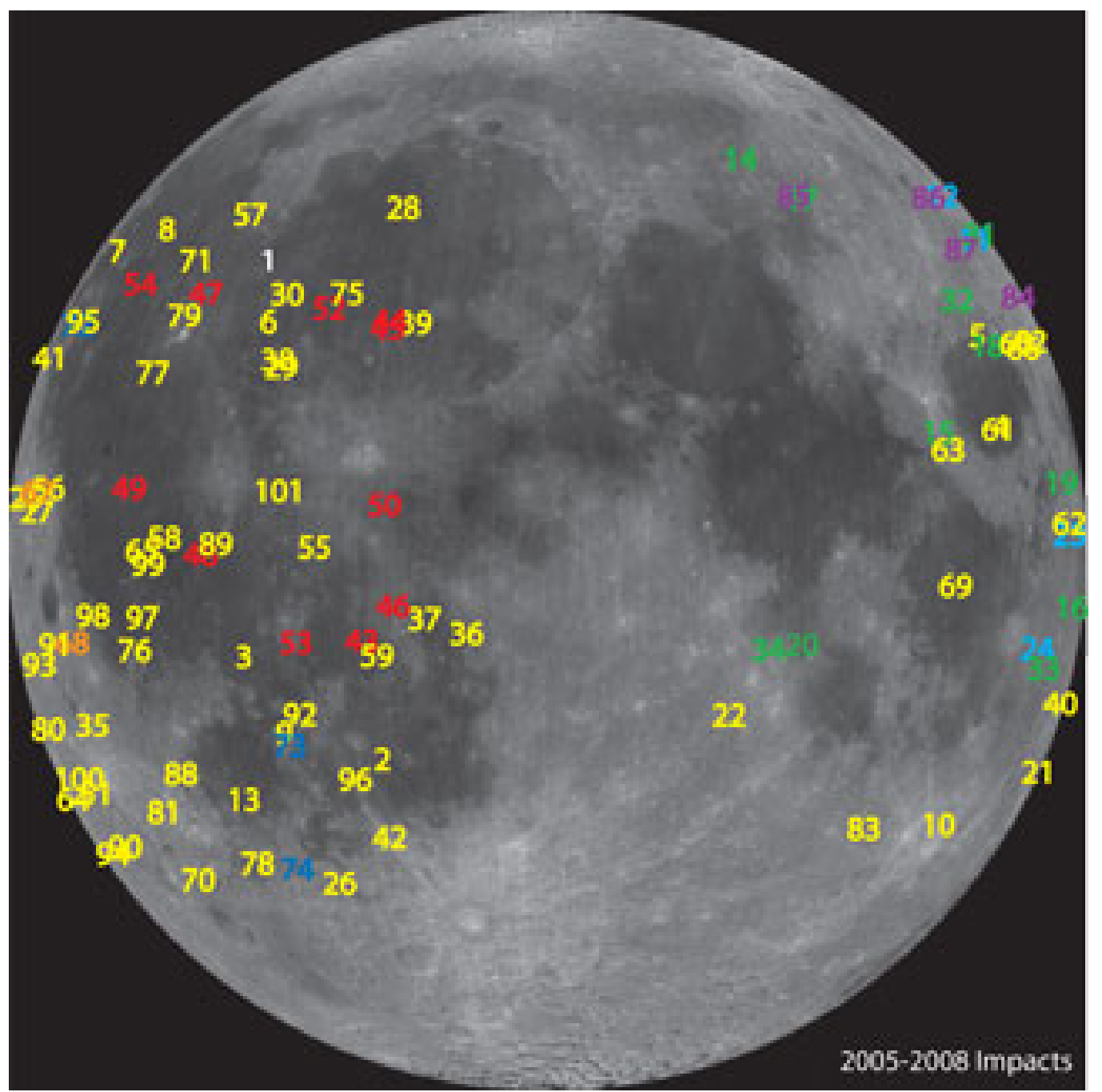

Yellows are sporadic meteoroids

Other colors are probable shower meteoroids 


\section{Sporadics Only thru March 08}

Evening obs 45 impacts in approx. 93 hours

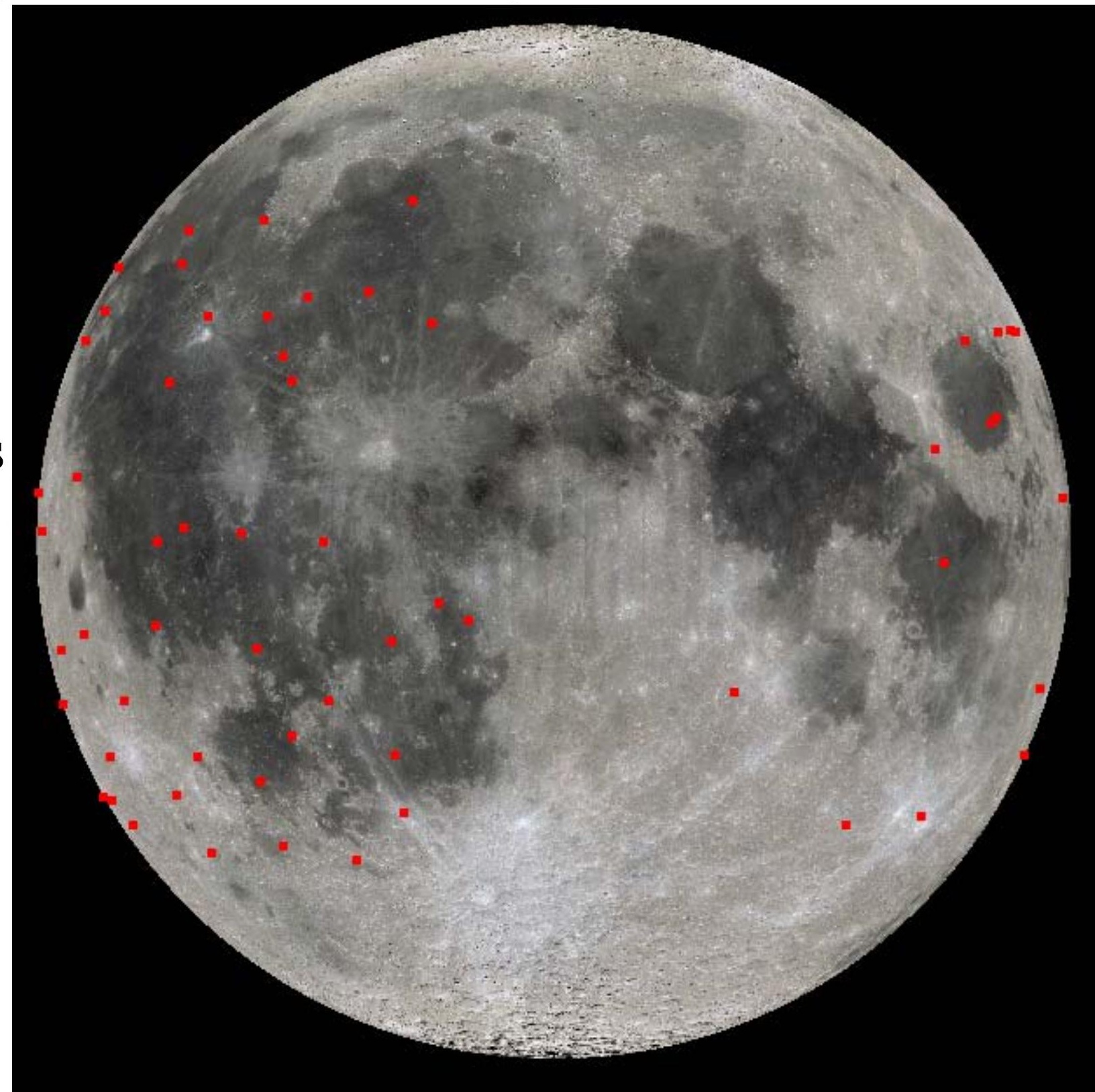

Morning obs 14 impacts in approx. 99 hours 


\section{Lunar Viewing and Impact Geometry from 3 In-plane Sporadic Sources}

Implies an average of more than 3 kilogram-class sporadic impacts per hour somewhere on the moon during non-shower periods

First Quarter

Anti-Helion

$24 \mathrm{~km} / \mathrm{s}$
Full

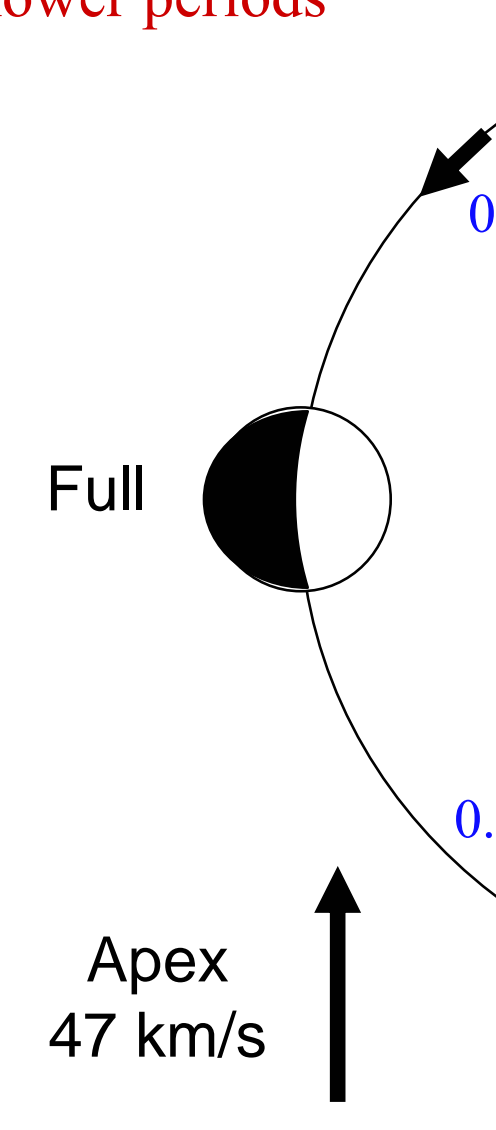

0.48 sporadic impacts/hour

93.6 hours of good video $48.6 \%$ of observing time 


\section{Sporadics Only thru March 08}

Evening obs 45 impacts in approx. 93 hours

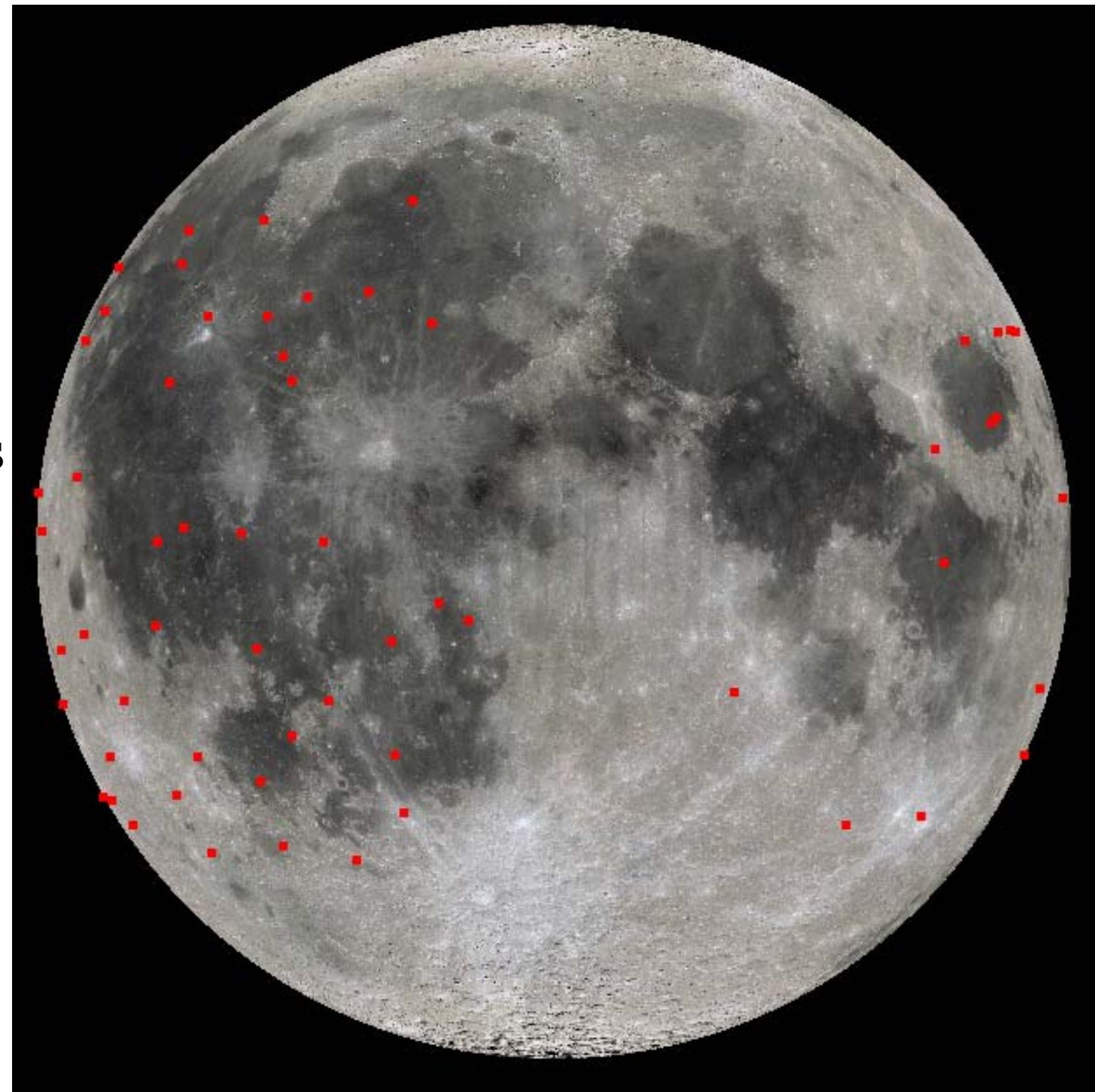

Morning obs 14 impacts in approx. 99 hours 


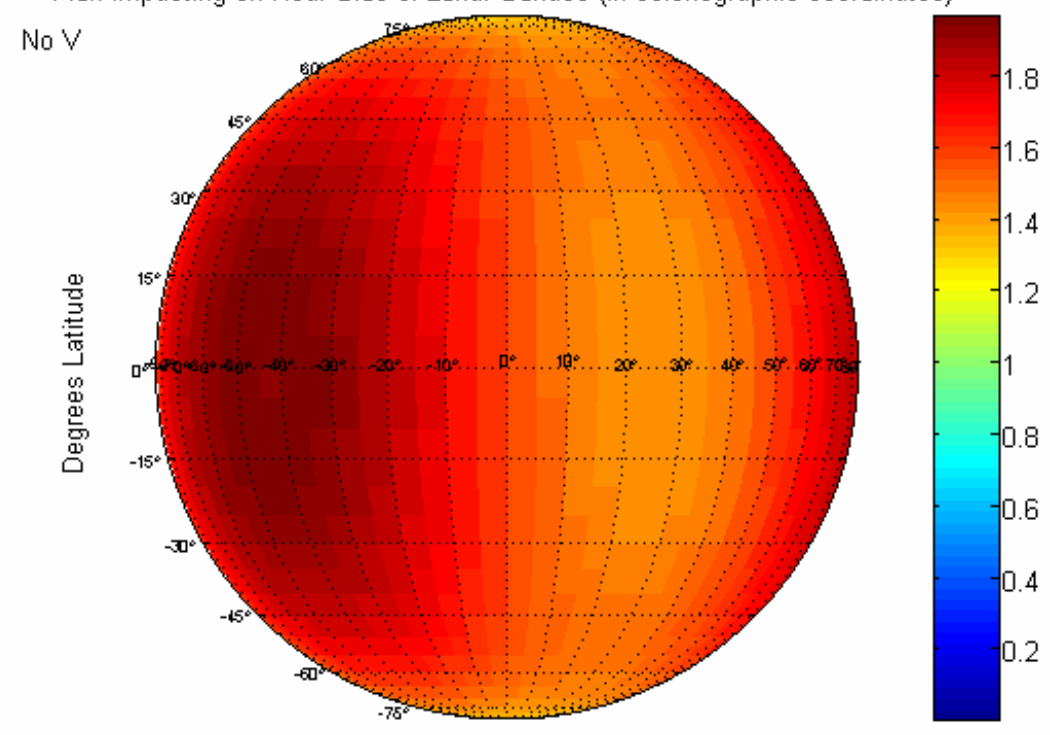

1 State $10 / 27 / 0622: 59 \mathrm{pm}$

Degrees Longitude

.31 Phase Evening Observation

No V Scaling Flux only

Flux Impacting on Near Side of Lunar Surface (in selenographic coordinates)

\section{Preliminary MEM Flux Calculations by Heather McNamara}

Flux Impacting on Near Side of Lunar Surface (in selenographic coordinates) $\vee^{2}$

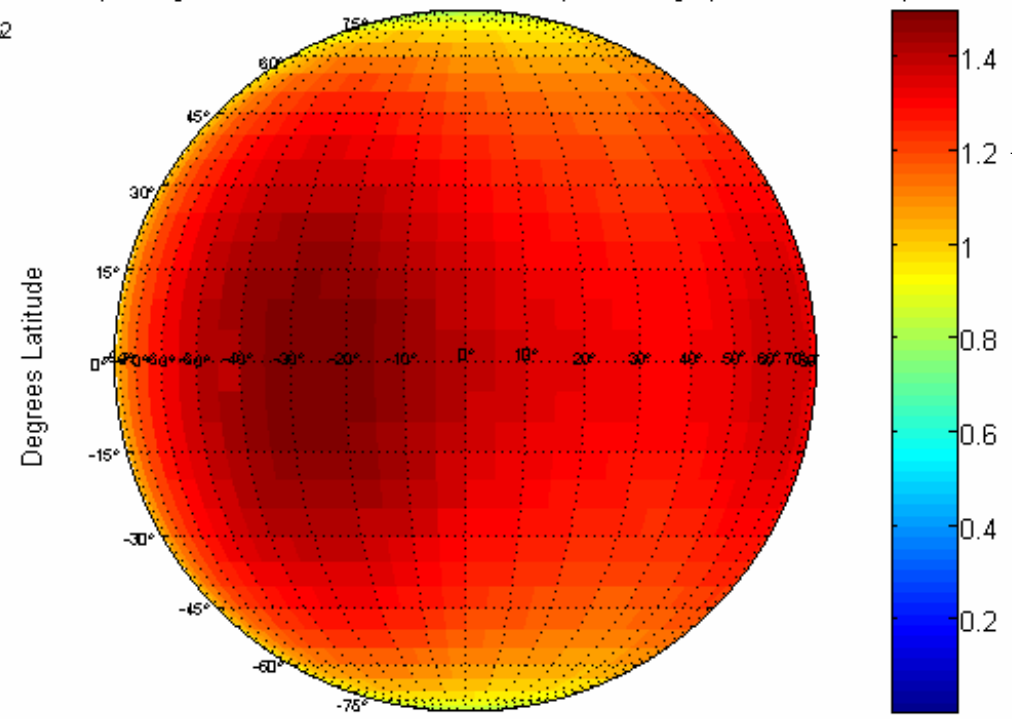

Flux Impacting on Near Side of Lunar Surface (in selenographic coordinates)

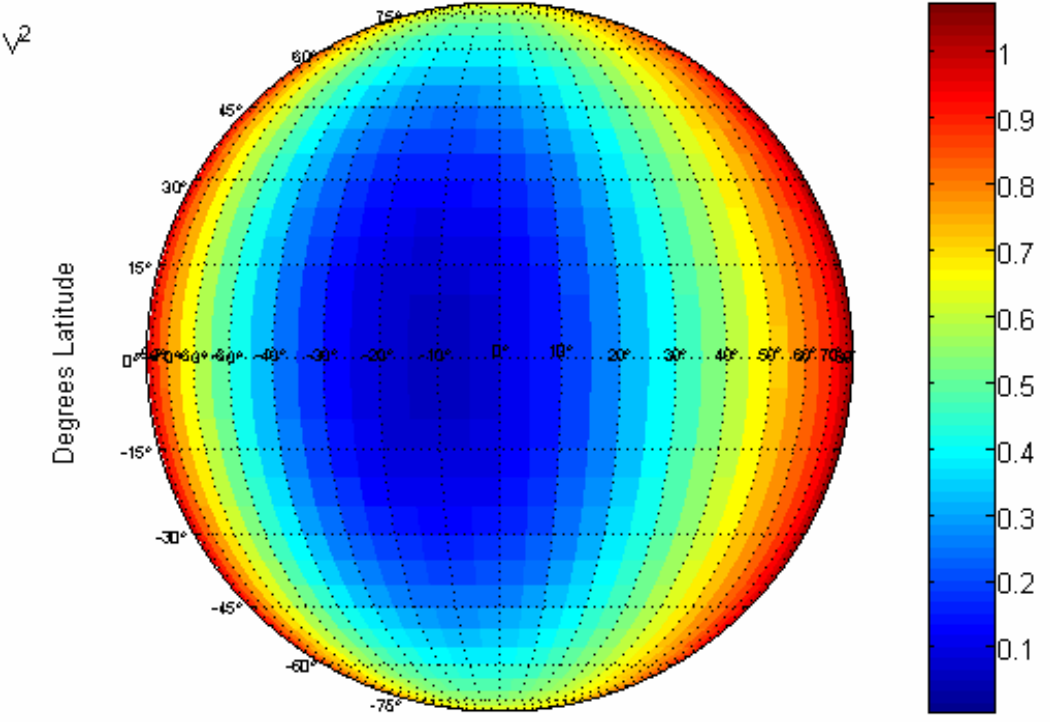


Sporadics Only thru March 08

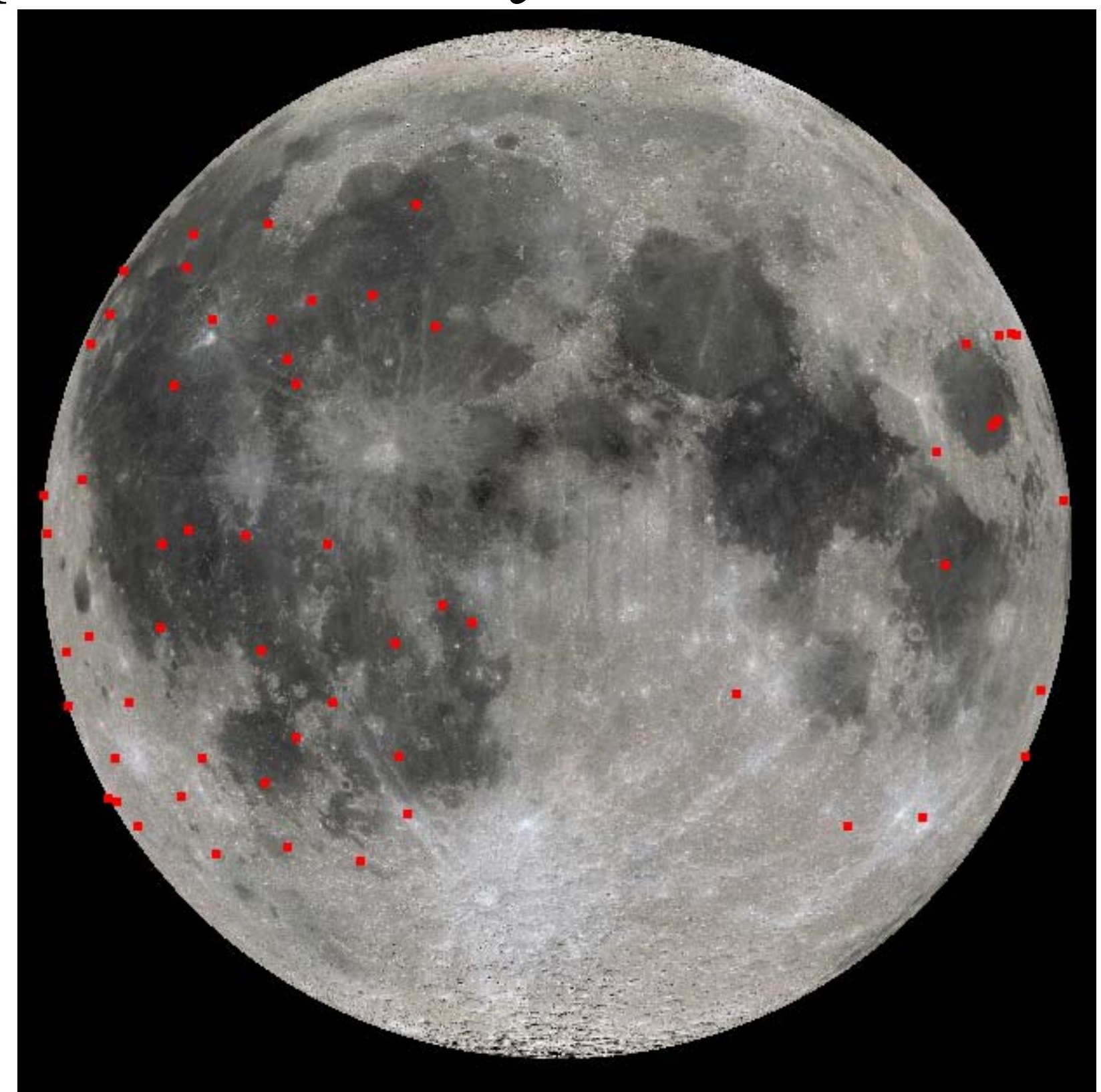


Flux Impacting on Near Side of Lunar Surface (in selenographic coordinates)

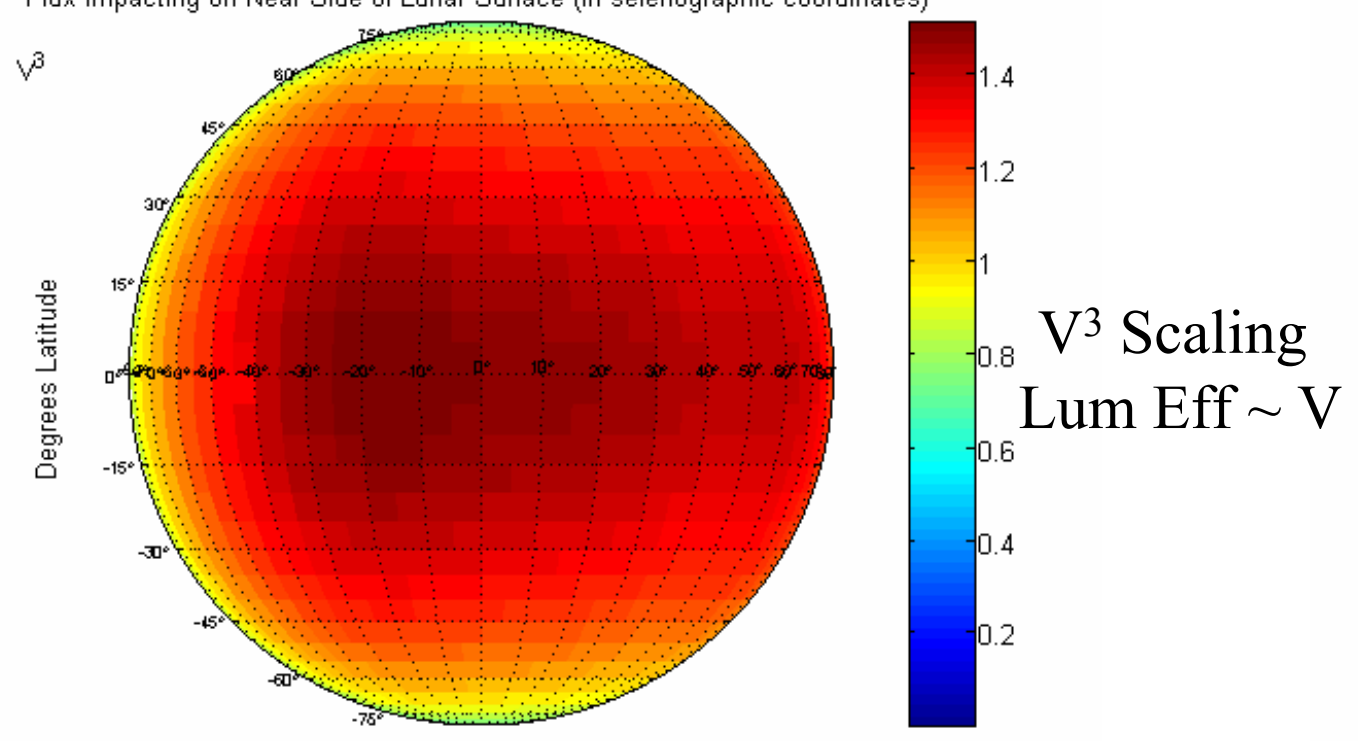

1 State 10/27/06 22:59 pm Degrees Longitude

.31 Phase Evening Observation

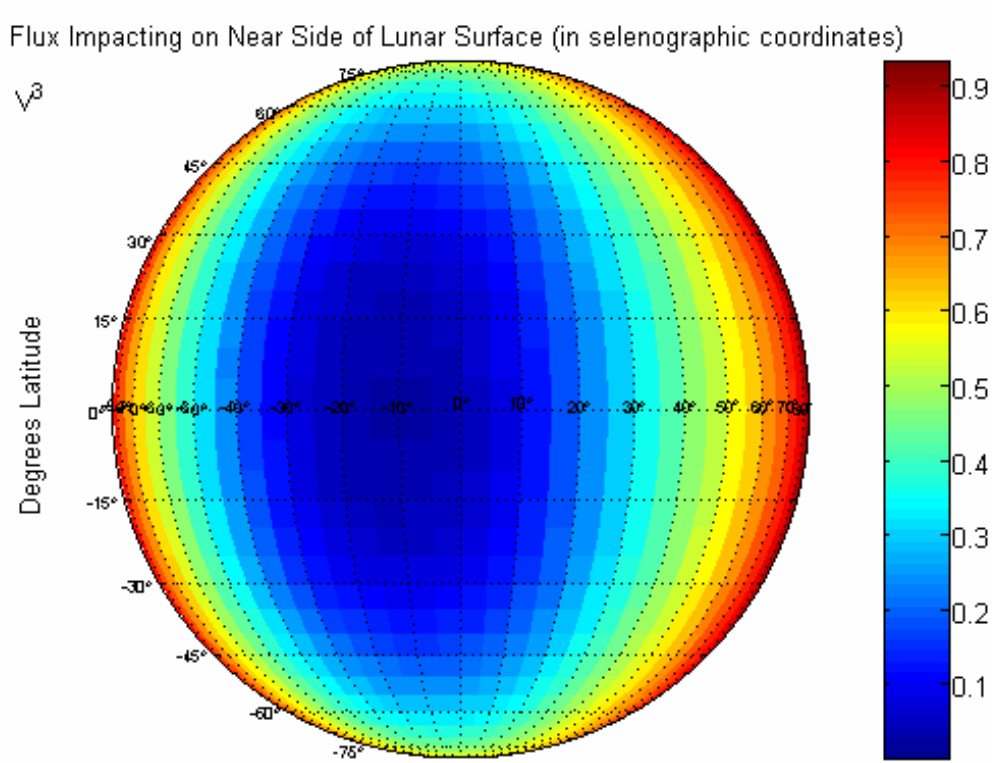

1 State $6 / 20 / 0603: 50$ am

Degrees Longitude

.30 Phase Morning Observation

\section{Preliminary MEM Flux Calculations by Heather McNamara}

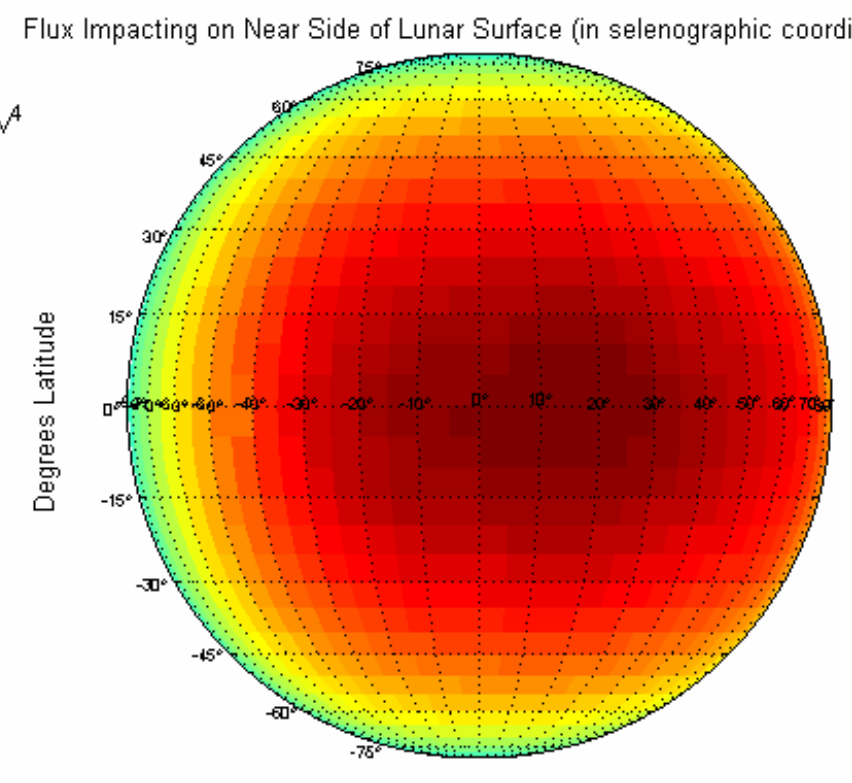

1 State $10 / 27 / 0622: 59 \mathrm{pm}$
$\mathrm{V}^{4}$ Scaling

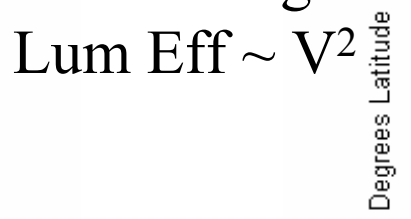

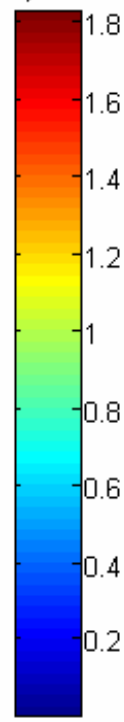

Flux Impacting on Near Side of Lunar Surface (in selenographic coordinates)

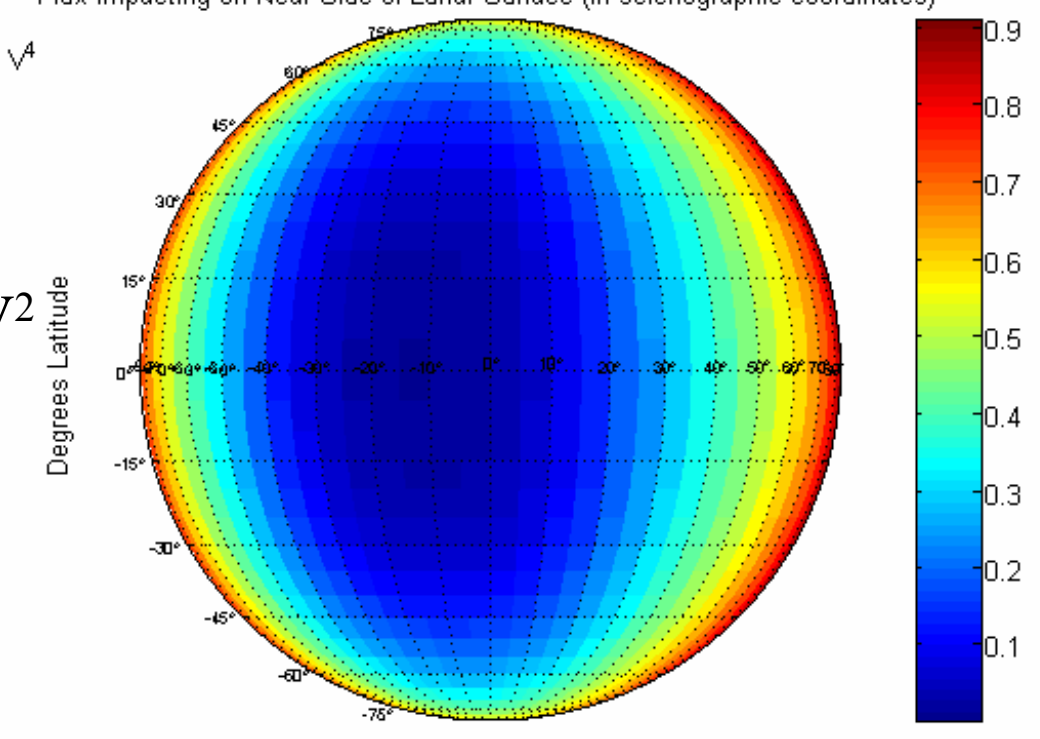




\section{Example of a Moderate-Sized Impactor - May 2, 2006}

Duration of flash: $\sim 500 \mathrm{~ms}$

Estimated peak magnitude: 6.86

Peak power flux reaching detector: $4.94 * 10^{-11} \mathrm{~W} / \mathrm{m}^{2}$

Total energy flux reaching detector: $4.58 * 10^{-12} \mathrm{~J} / \mathrm{m}^{2}$

Detected energy generated by impact: $3.394 * 10^{7} \mathrm{~J}$

Estimated kinetic energy of impactor: $1.6974 * 10^{10} \mathrm{~J}(4.06$ tons of TNT)

Estimated mass of impactor: $17.5 \mathrm{~kg}$

Estimated diameter of impactor: $32 \mathrm{~cm}\left(\rho=1 \mathrm{~g} / \mathrm{cm}^{3}\right)$

Estimated crater diameter: $13.5 \mathrm{~m}$ 


\section{Ames Hypervelocity Impact Testing}

- Purposes

- Determine impact luminous efficiency - fraction of kinetic energy converted to light (completed 2 sessions of tests for this)

- Determine size and velocity distributions of ejecta produced in cratering process

- Fired pyrex projectiles into pulverized pumice and JSC-1A simulant at various speeds and angles

- Preliminary testing completed in October ' 06

- Recorded impacts with our video cameras and Schultz's high speed photometer using ground pumice

- Second test sequence completed August '07

- True neutral density filters on our video cameras using JSC-1A simulant 


\section{Ames Vertical Gun Range}

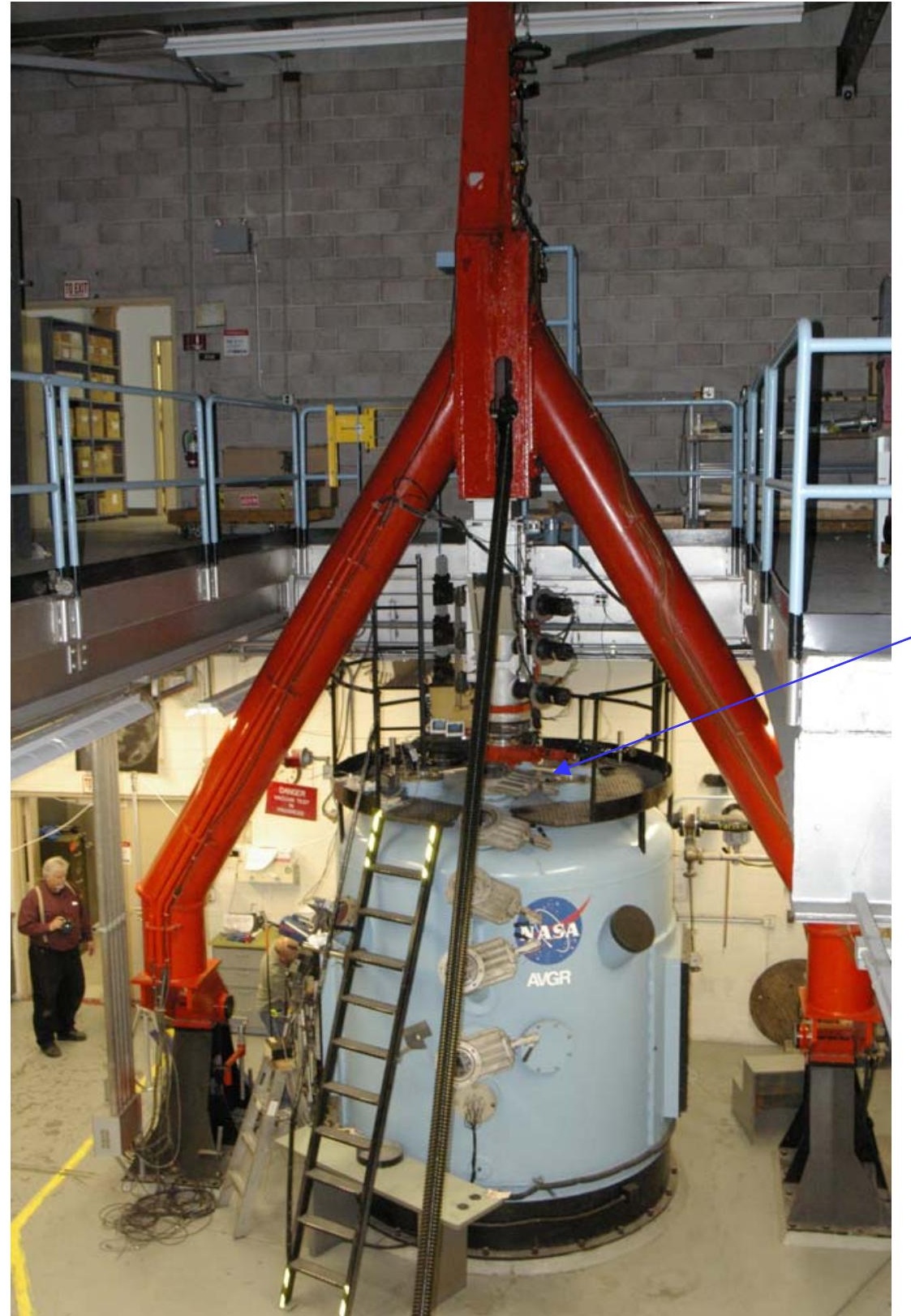

Camera ports 


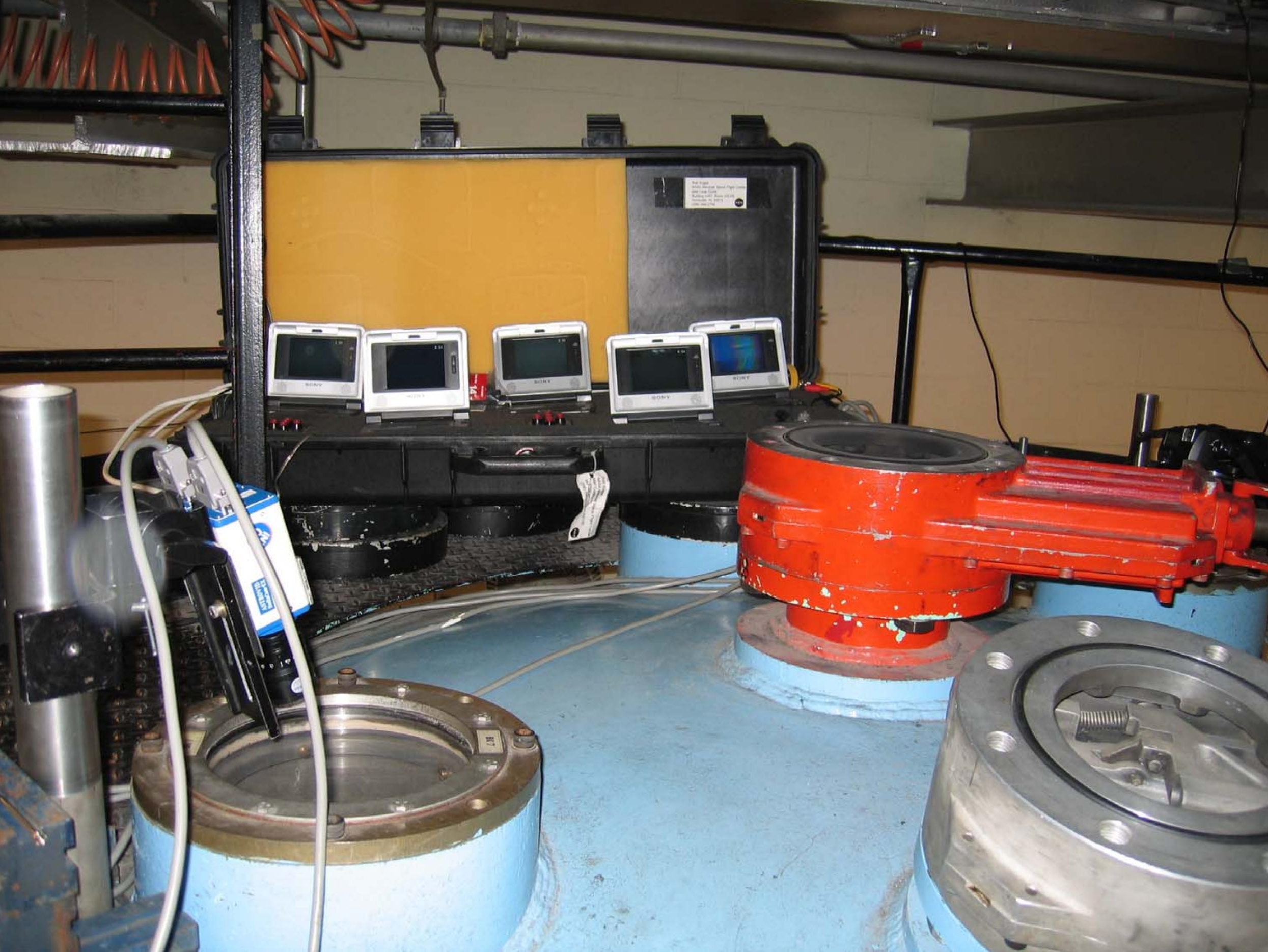




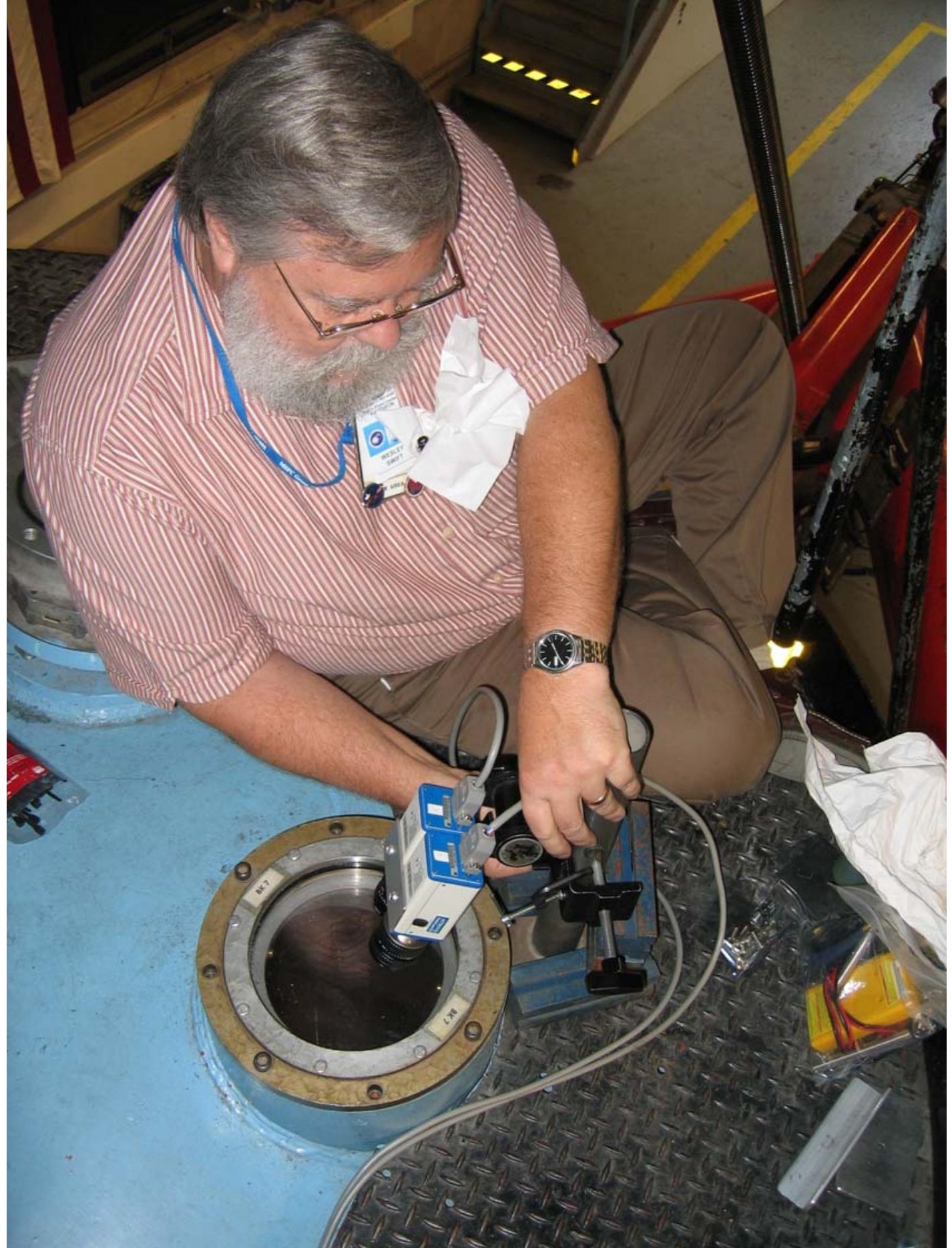




\section{AVGR - Shot 10}

Projectile: 0.25" Pyrex Target: Pumice Powder Speed: $5.32 \mathrm{~km} / \mathrm{s}$ 45 deg. impact angle 
AVGR Run 070823 


\section{Crater in JSC-1A Simulant}

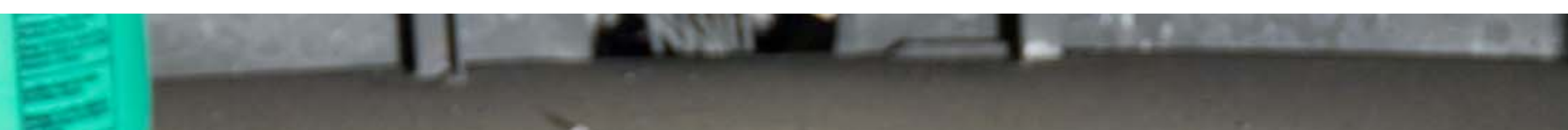




\section{Preliminary Results}

using "not so neutral" density filters

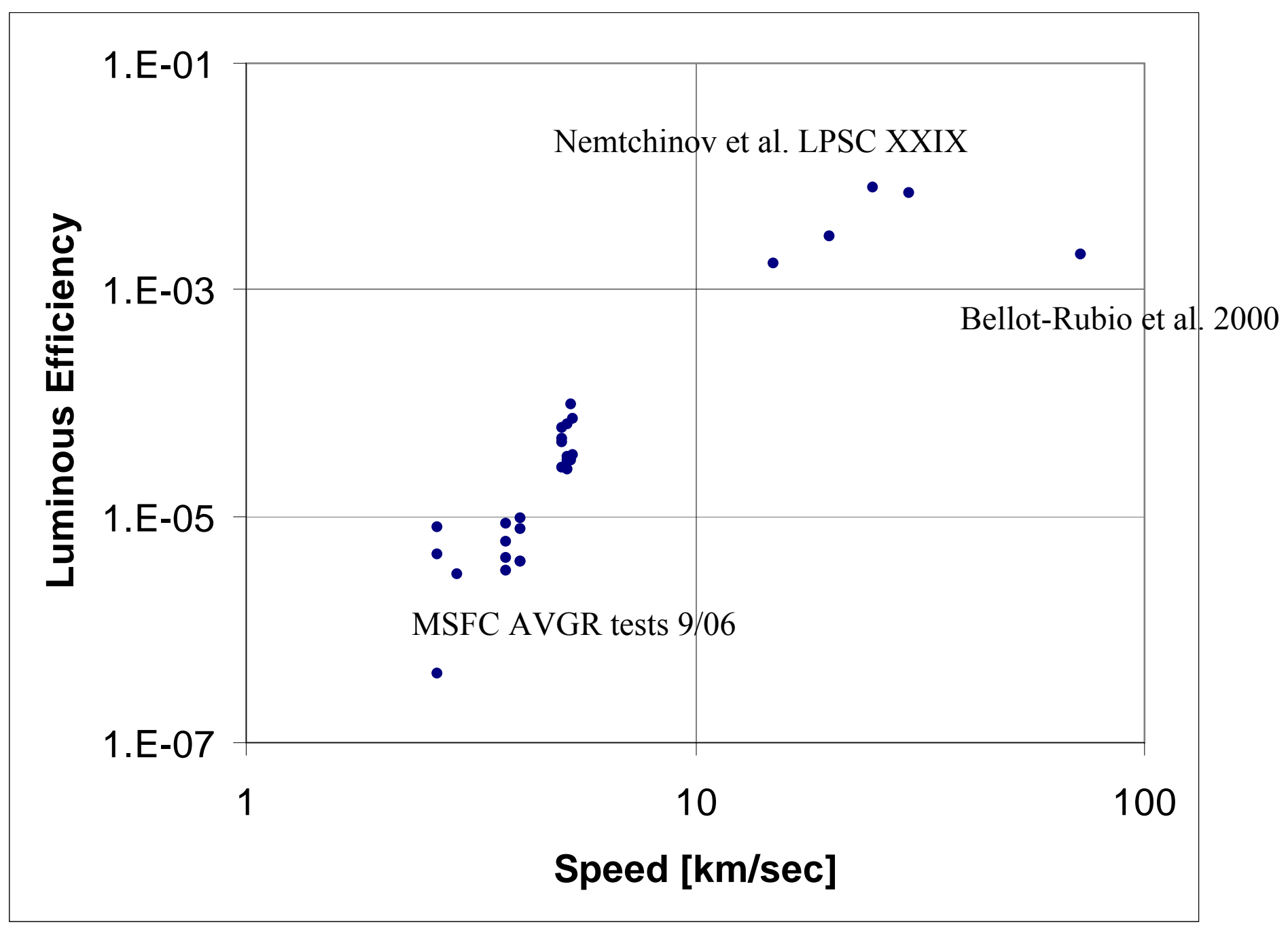




\section{Next Step - Measure Ejecta Properties}

- Designers need speed, size, and direction distributions to optimize meteoroid shielding designs

- Very high speed camera or sheet laser measurements of hypervelocity shots are needed to determine these characteristics

- Modeling to scale from AVGR tests to lunar sizes and velocities 


\section{Stopping time: watching craters grow 170 millionths of second}

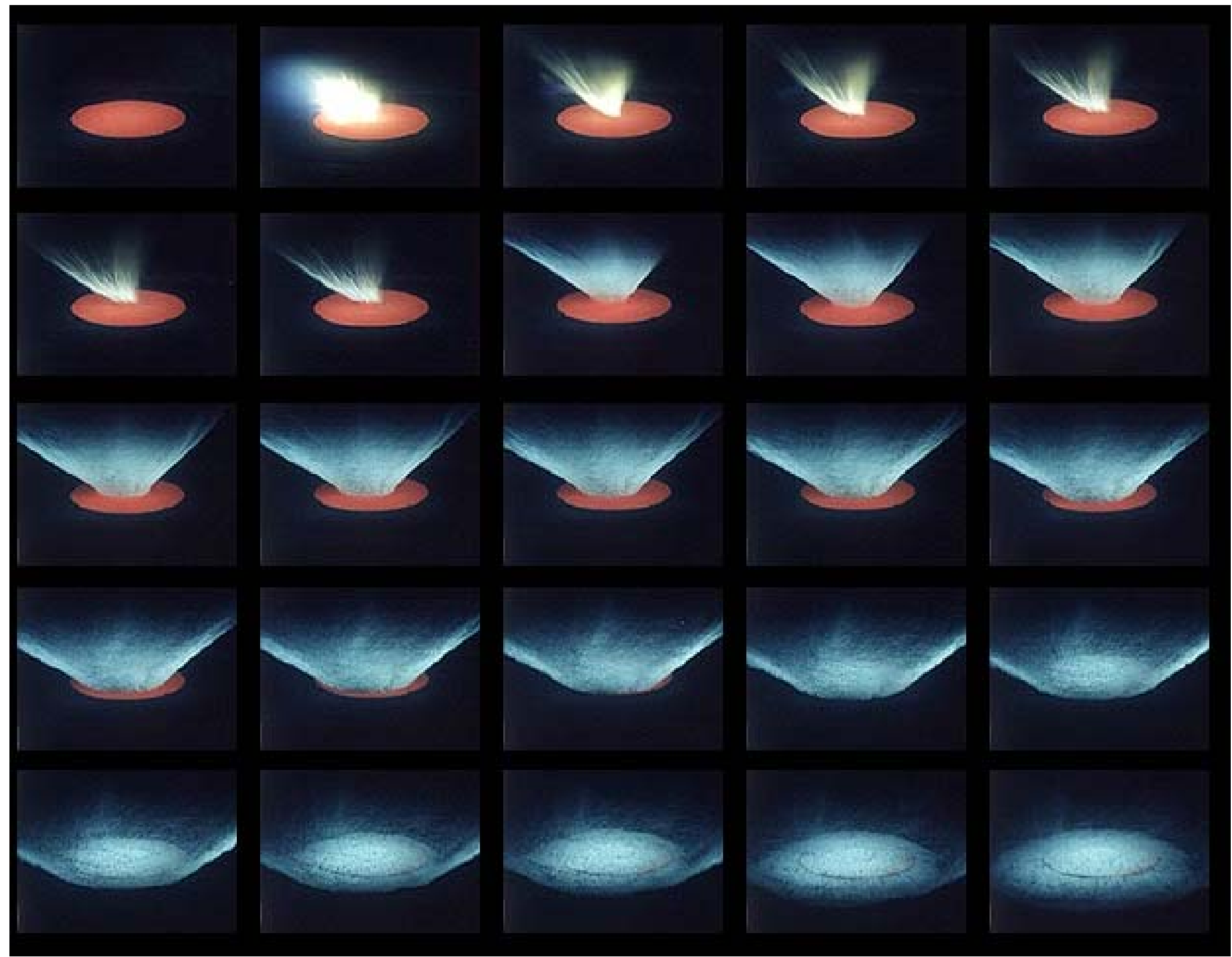

Schultz, et al. 


\section{Ejecta Flight Model Very Preliminary Model Test Results Simple assumed ejecta distribution}

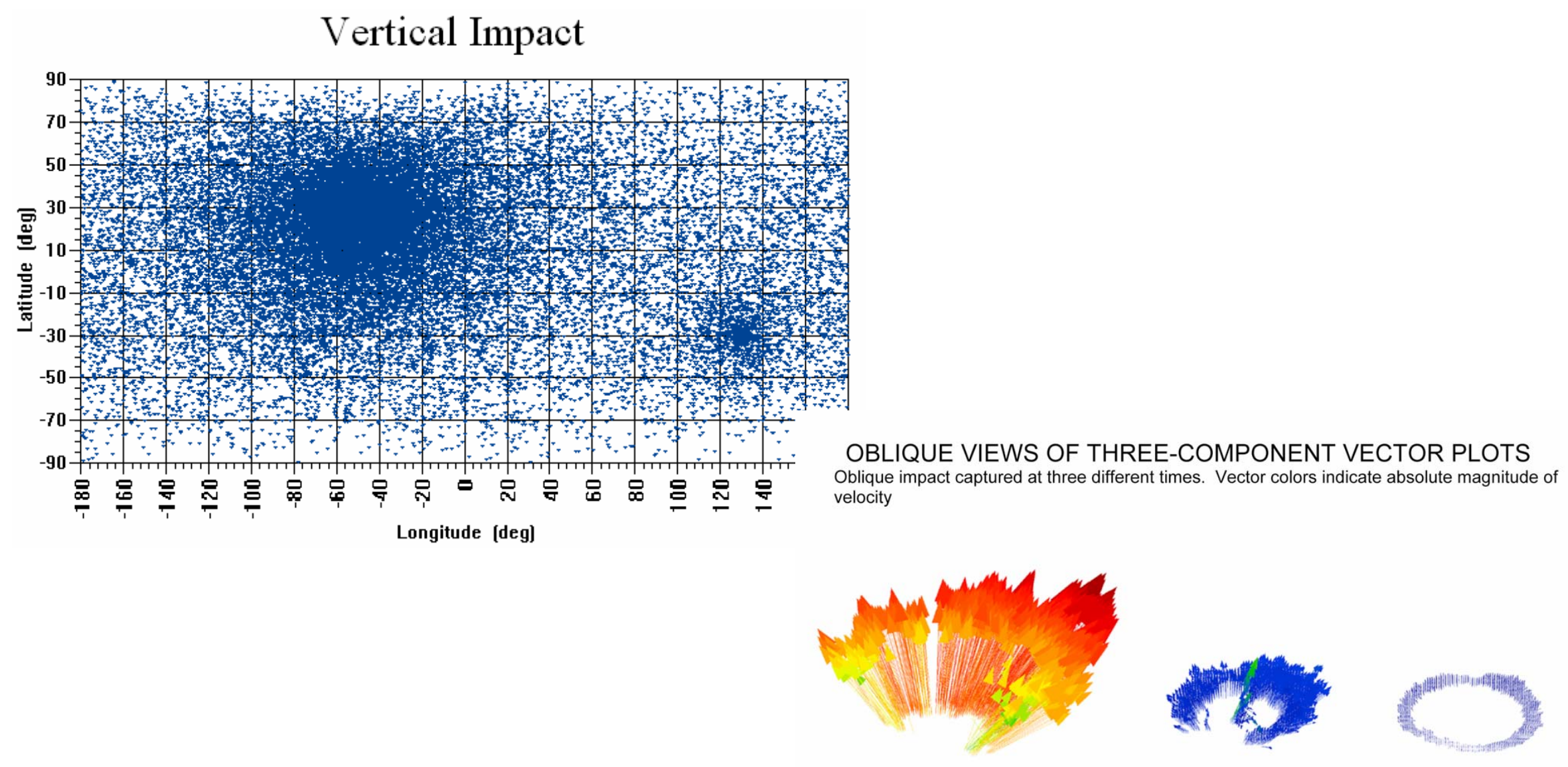

Absolute Magnitude of Velocity, $\mathrm{m} / \mathrm{s}$ 


\section{Plans}

- Continue impact monitoring into the foreseeable future

- Perhaps add an infrared camera since flashes peak redward of 1 micron

- Observe LCROSS impact from Apache Point Observatory

- $3.5 \mathrm{~m}$ and one of our 14 inch scopes to measure ejecta plume

- Complete analysis of observational data and present at DPS this October

- Analyze latest AVGR photometric data to determine luminous efficiency at low speed/size

- Previous data was taken with "non-neutral" neutral density filters

- If/when Constellation funding becomes available, begin ejecta characterization and modeling tasks and develop engineering model of the ejecta environment 


\section{Summary}

- We have a fruitful observing program underway which has significantly increased the number of lunar impacts observed

- We have done initial test shots at the Ames Vertical Gun Range - obtained preliminary luminous efficiency values

- More shots and better diagnostics are needed to determine ejecta properties

- We are working to have a more accurate ejecta environment definition to support lunar lander, habitat, and EVA design

- Data also useful for validation of sporadic model at large size range 


\section{Useful Links}

- MEO http://meo.nasa.gov

- Impacts

http://www.nasa.gov/centers/marshall/news/lunar/index.html 